\title{
Water Vaporization from Deposited Sand by Microwave Cavity Resonator
}

Hiroshi Yokawa', Hirokazu Mutou', Shuntaro Tsubaki ${ }^{2}$, Naoto Haneishi², Takashi Fuji', Norio Asano', Keiichiro Kashimura1*, Tomohiko Mitani $^{3}$, Satoshi Fujii',4, Naoki Shinohara ${ }^{3}$ and Yuji Wada ${ }^{2}$

${ }^{1}$ Chubu University, 1200 Matsumoto-cho, Kasugai, Aichi 487-8501, Japan

${ }^{2}$ Department of Chemical Science and Engineering, School of Materials and Chemical Technology, Tokyo Institute of Technology, Ōokayama 2-12-1, Meguro, Tokyo 1528552, Japan

${ }^{3}$ Kyoto University, Gokasho, Uji, Kyoto 611-0011, Japan

${ }^{4}$ Okinawa National College of Technology, Department of Information and Communication System Engineering, 905 Henoko, Nago-city, Okinawa, Japan

\begin{abstract}
In this study, water-soil moisture heating behavior, water vapor rates, and the effect of soil-aggregating agent permittivity under a $2.45-\mathrm{GHz}$ microwave cavity resonator were investigated. The conducted experiments indicated different orders of magnitude than the drying furnace process in the water evaporation rate; moreover, the water vapor rate increased in accordance with the microwave power. The microwave absorption properties indicated that microwave selectively heated water into vaporized moisture, and the vaporization conformed to an energy balance between water evaporative latent heat and microwave power. Furthermore, soil-aggregating agents showed minimal effects on the vapor rate at low microwave power, whereas sand deposited with an aggregating agent indicated a higher vapor rate than that without an agent at a high microwave power. When sufficient energy was supplied to moisture, water transfer was dominant in the vaporization process. In this case, the soil-aggregating agents significantly affected the efficiency of the vaporization process.
\end{abstract}

Keywords: Soil-aggregating agent permittivity; Water-soil moisture heating behavior; Microwave of cavity resonator

\section{Introduction}

Microwaves (MWs) have been extensively studied as an alternative energy source in various applications, including engineering process heating [1,2]. Ishizaki and Nagata [1] constructed a high-power (120$\mathrm{kW}$ ) continuous $2.45-\mathrm{GHz} \mathrm{MW}$ furnace for steel production. Similarly, Peng et al. [2] constructed a 915-MHz 225-kW MW furnace to scale up steel production. Roy et al. indicated that MWs can heat metal particle compacts [3]. The MW heating mechanism has been studied over several decades with the objective of designing efficient selective heating, which is an important property of MW heating [4,5]. In these processes, MWs have been shown to be a special heating source with a selective heating property, because materials change their heating behaviors in accordance with their absorption properties.

Many advantages exist in terms of the compact apparatuses and rapid heating in MW methods, especially in recycling processes required for onsite treatments. MW technology compresses the asbestos degrading time from $10 \mathrm{~h}$ to $30 \mathrm{~min}$ through only a rapid energy supply [6]. In general, asbestos can be degraded at the temperature of $1000^{\circ} \mathrm{C}$ or higher. However, in treating large amounts of asbestos-contaminated cement material, it is difficult to heat the interior of the material because of its low thermal conductivity. In this case, MWs do not supply energy to materials through thermal conductivity; rather they supply energy via MW field potential. The use of MW energy provides a significant speed advantage while transforming hazardous waste into non-hazardous materials. This is because, in the case of asbestos-cement materials, MW energy is applied via an alternating electric field. The electric permittivity and MW emissive strength determine the temperature at the center of the asbestos-contaminated cement materials. The MW heating system is very compact. Hence, by leveraging the above advantages, we established a test apparatus with a 2 ton/day asbestos treatment capacity at an affected area of the 2011 Tōhoku, Japan earthquake in only 13 days [7]. MW heating enabled the asbestos degrading process to heat the material in-situ because of the rapid heating capability.

Moreover, the soil is obtained in a grit chamber for MW technology. The construction of buildings near a grit chamber produces soil with inadequate water. If the water content is controlled on site, this soil can be readily employed as backfill and cement materials. This concept is very reasonable in terms of recycling, because fine-grained soil is a material suitable for back-filling, after the moisture is controlled. Furthermore, Miura et al. reported a construction method to utilize water-absorbing polymer for sludge recycling [8]. This method is effective for the recycling of sludge having a water content ratio of $100 \%$ or less, and it can be applied to various kinds of sludge by leveraging the hydration reaction with it. Mori et al. reported a recycling method of high-water content mud by using paper debris and polymer [9]. They employed the paper debris for controlling water content of mud and developed a method that can modify mud with $200-500 \%$ water content. Kamon et al. reported a dehydration-solidification treatment system of waste slurry from construction works [10]. They proposed a continuous dehydration-solidification treatment system to utilize the sludge materials and evaluate them in terms of economy and efficiency.

Despite the above advancements, these methods are time-intensive and require large spaces. For MW methods, many researchers have reported MW vaporization of water contents in sand [11-15]. Kawala et al. conducted large-scale investigations to establish the effective moisture control system by MW heating. They demonstrated MW water vaporization from the soil to establish an MW heating system with array antennas, and they demonstrated their economic efficiency [13]. Appleton et al. discussed the potential use of MW technology as an energy-efficient alternative to current heating technologies by employing the processing and treatment of waste [14]. The applications of processing considered were the treatment and control of specific, and often problematic, waste streams, including scrap tires and plastics, and the remediation of contaminated land and groundwater. Varba et

*Corresponding author: Keiichiro Kashimura, Chubu University, 1200 Matsumotocho, Kasugai, Aichi 487-8501, Japan, Tel: (+81) +568-51-8420; Fax: (+81)+568-518421; E-mail: kashimura@isc.chubu.ac.jp

Received June 23, 2017; Accepted August 21, 2017; Published August 24, 2017

Citation: Yokawa H, Mutou H, Tsubaki S, Haneishi N, Fuji T, et al. (2017) Water Vaporization from Deposited Sand by Microwave Cavity Resonator. J Civil Environ Eng 7: 279. doi: 10.4172/2165-784X.1000279

Copyright: @ 2017 Yokawa H, et al. This is an open-access article distributed under the terms of the Creative Commons Attribution License, which permits unrestricted use, distribution, and reproduction in any medium, provided the original author and source are credited. 
al. reported MW treatments to remediate contaminated solids [15]. Their work focused on MW-assisted thermal treatments of waste from a physical-chemical perspective. They reported two respective recovering operations: one on the soil contaminated by volatile organic compounds; the other on a ceramic filter spoiled by soot. To this end, they used two specially designed prototypes that were realized on a prepilot scale. Nevertheless, there have been few studies on developing an experimental approach to understanding the water vaporization mechanism from the soil.

To efficiently control moisture content of fine-grained soil from construction of buildings and bridges by MW, a cavity resonator method is thus proposed that can focus the MW energy on water. By employing this method, an efficient and accurate estimation process for MW can be obtained. At first, we first investigated the time dependence of the temperature of the soil with water, which was obtained in a grit chamber, as $\mathrm{E}_{\max }$ (the electric node $\left(\mathrm{E}_{\max }\right)$ of the MWs could be obtained in a cavity). In this experiment, the effects of a pure electrical field on water vaporization in soil were investigated. Next, electrical permittivities of water and soil were measured to elucidate the heating mechanism of the soil in MW methods. The energy transfer from MWs to the soil-water mixture of each electric field was measured and compared with predictions based on Maxwell's equation. The effects of soil aggregating agents were examined to understand their vaporization mechanism in MW technology.

\section{Experiments}

\section{Materials}

Soil: Sand deposits obtained from a grit chamber (Nanno, Kaidu City, Gifu, Japan) with a highly fine grain percentage were used as samples. The properties of the soil were measured according to the guidebook of Japanese Industrial Standards (grain density: $2.71 \mathrm{~g} / \mathrm{cm}^{3}$; optimum water content: $14.90 \%$; $50 \%$ particle size: $0.02 ; 20 \%$ particle size: 0.0035 ; uniformity coefficient: 19.98 ; curvature coefficient: 1.51 ; liquid limit: 26.20) [16].

Water: Distilled water was employed in this measurement.

Soil-aggregating agents: GB 2000 agents (polymer aggregating agents) were employed as soil-aggregating agents. GB 2000 agents were adequate for this study-a comparative study using the MW method as the conventional method-because they are commonly employed as aggregating agents in the natural drying method. The GB 2000 agents were used after dilution with 50x distilled water.

\section{Apparatus}

Heating system (cavity resonator): Figure 1 shows the MW heating system used in the experiments. It had a magnetron (MPS-17A, Nisshin Engineering Corp.; frequency: $2.455 \mathrm{GHz} \pm 15 \mathrm{MHz}$; output power: 1.5 $\mathrm{kW})$. MWs from the magnetron irradiated a soil-water mixture and heated it. The heating system consisted of a waveguide cavity $(109.1 \times$ $56.4 \times 149.3 \mathrm{~mm} \pm 5 \mathrm{~mm}$ ) with a magnetron oscillator, an auto E-H tuner, a plunger, and a dummy road. The MWs were focused by an iris and formed a TE103 wave in this cavity. (In the transverse electric (TM) mode, there is no electric field in the direction of wave propagation.) The iris had a $28-\mathrm{mm}$ slit that was parallel to the direction of the electric field. The plunger was placed at the end of the cavity. This system enabled spatial separation of the electric and magnetic fields of the MWs [17].

Cavity perturbation method: We used a cavity perturbation method $[18,19]$ to obtain real and imaginary parts of sand permittivity. The measurement system consisted of a cylindrical cavity and a network

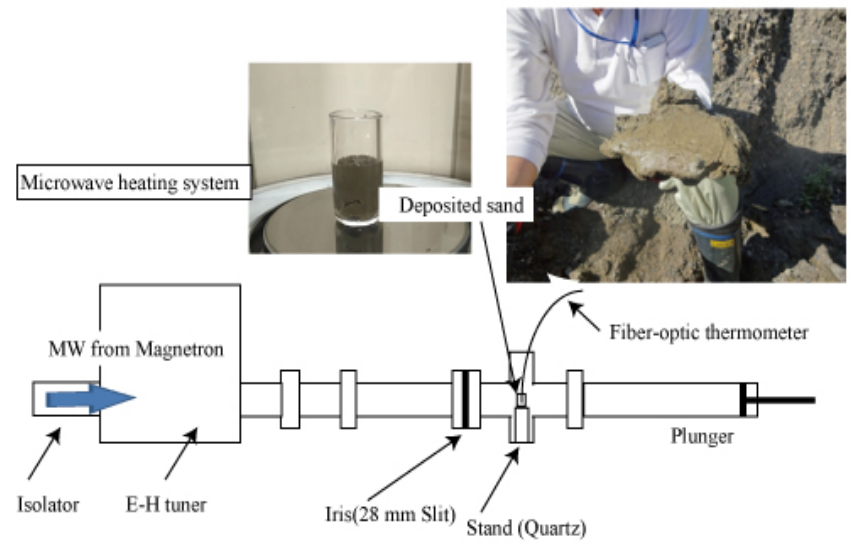

Figure 1: Deposited sand and microwave heating system.

analyzer (Advantest R3767CG). Quartz tubes have a negligible effect on MW distribution; therefore, a silica tube was used as the sample holder. The sand was positioned in the center of the cavity and its electrical permittivity was monitored.

Coaxial probe method: To measure the permittivity of water, the coaxial probe method was employed [20]. The system consisted of a network analyzer (Agilent N5242A) and probe kit (Agilent 85070E). The pure water, water-soil mixture, and filtrated water were employed as the samples.

\section{Microwave drying}

Sample preparation: To obtain sand with a water-liquid index, sufficient distilled water was mixed into the sand. The mixture was covered by a film and retained for 7 days.

Microwave heating: In this study, the MW power (or holding time at the temperature of $100^{\circ} \mathrm{C}$ ) was varied as parameters. Before the MW treatment, the mixture was separated into a quartz component holder with a diameter of $12 \mathrm{~mm}$ and length of $10 \mathrm{~mm}$ quickly. The obtained sample included $1.5 \mathrm{~g}$ to $1.6 \mathrm{~g}$ of water per $10 \mathrm{~g}$ of mixture. To prevent the explosion of the sample by rapid heating, the soil-water mixture was filled at a height that is $1 / 2$ of that of the sample holder.

The sample was placed at an electric-field node (denoted by $\mathrm{E}_{\max }$, where the magnetic field was considerably weak). MW heated these samples and the temperature of the reactants was monitored using a fiber optic thermometer. The fiber optic thermometer was embedded in the sample center before the MW was on. The temperature of deposited sand increased with the MW on, was maintained at $100^{\circ} \mathrm{C}$ for intervals, and then increased at the temperature of $100^{\circ} \mathrm{C}$ or higher. In this study, this series of temperature behavior was defined as one measurement. After MW irradiation, we quickly wrapped the sample holder to prevent the water from vaporizing. The evaporation amount was calculated from the mass change before and after treatment.

\section{Electrical permittivity}

In this condition, the surrounding medium of sand had a notable effect on the absorption properties of water. In this case, the important properties were electrical conductivities of ions from sand and the shapes of particles. To investigate these effects, the electrical permittivities of sand and water were respectively measured.

Soils: We used the cavity perturbation method to obtain real and imaginary parts of permittivity of sand. When $9 \mathrm{~mm} \times 9 \mathrm{~mm}$ samples 
were moved into the cavity, they disturbed the $\mathrm{Q}$ factor and resonance frequency of the cavity because of their material properties. The network analyzer monitored the $\mathrm{Q}$ factor and resonance frequency of the system. The cavity exhibited the TM010 mode, where a perturbation coefficient of 1.848 was employed. (In the transverse magnetic (TM) mode, there is no magnetic field in the direction of wave propagation.) The electrical permittivity was estimated by both the $\mathrm{Q}$ factor and resonance frequency of the cavity $[14,15]$.

Water: To measure the permittivity of water, the coaxial probe method was employed. In the coaxial probe method, the electric permittivity of the solution is calculated from the reflection coefficient of the electromagnetic waves of the coaxial probe-solution interface, which is prepared by soaking the probe. In this study, the water and soil mixture were prepared as a sample solution. The solution was maintained in a beaker, the probe was soaked in the solution, and subsequently weak electromagnetic waves at frequencies of $500 \mathrm{MHz}-8.0 \mathrm{GHz}$ were irradiated. The network analyzer detected forward and reflected MW. The real part, imaginary part, and loss tangent were calculated from these MW parameters by employing the NIST precision method [20].

\section{Results and Discussion}

Figure 2 depicts the heating behavior of $10 \mathrm{~g}$ of deposited sand sampled from the grit chamber with $1.5 \mathrm{~g}$ to $1.6 \mathrm{~g}$ of water. In this experiment, the microwave power was set to $120 \mathrm{~W}$ and the reflected power was below $10 \mathrm{~W}$. The temperature of deposited sand increased with the MW on (region A). It was then maintained at $100^{\circ} \mathrm{C}$ for intervals (region B). Region A indicates a more rapid ascent than region $\mathrm{B}$ in terms of temperature. As shown in the Figure 3a, the temperature behaviors are divided into three regions. The heating behavior of the mixture can be described as the energy balance as:

$$
\begin{aligned}
& w_{\text {in }}(\boldsymbol{T})=\frac{1}{2} \int_{V}\left(\omega \varepsilon_{r}^{\prime \prime}|E|^{2}+\omega \mu_{r}^{\prime \prime}|H|^{2}\right) d V \\
& w_{\text {out }}(\boldsymbol{T})=\int_{S} \alpha\left(T-T_{\text {air }}\right) d S+\iint_{V} \int_{i} \sum_{i} \rho_{i} C_{p}^{i} d T d V+\int_{S} \theta \delta T^{4} d S \\
& \omega_{\text {in }}(\mathrm{T})=\omega_{\text {out }}(\mathrm{T})=W_{p}-W_{p}
\end{aligned}
$$

where $\alpha$ is the heat transfer coefficient, $\mathrm{C}_{\mathrm{p}}{ }^{\mathrm{i}}$ is the enthalpy of $\mathrm{i}$ (water and soil), is the product of the Stefan-Boltzmann constant and the emissivity $\left(=5.67 \times 10^{-8} \mathrm{~W} \mathrm{~m}^{-2} \mathrm{~K}^{-4}\right)$, and $\theta$ is the emissivity. Moreover, $\mathrm{w}_{\text {in }}$ and $\mathrm{w}_{\text {out }}$ denote the input power into the mixture and energy extracted from the mixture, respectively (another form of equation. (1) includes the energy transition induced by the current; in this paper, we employ the above form). The real and imaginary parts of the relative permeability are $\varepsilon_{\mathrm{r}}^{\prime}$ and $\mathcal{E}^{\prime \prime}$, respectively. $\mathrm{W}_{\mathrm{Fp}}$ and $\mathrm{W}_{\mathrm{Rp}}$ denote the respective forward power and reflected power measured by the power monitor. In this

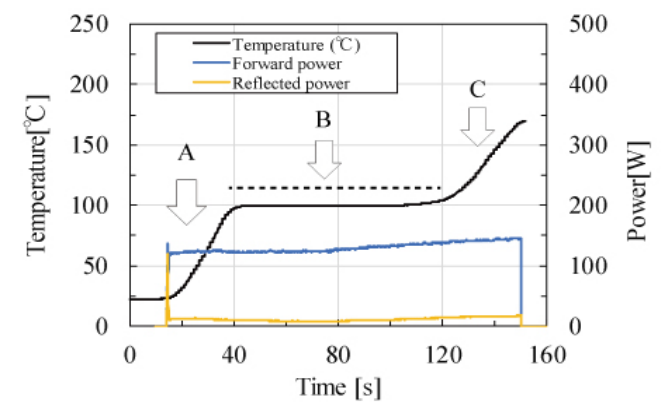

Figure 2: Time evolution of temperature for deposited sand sampled from a grit chamber (Nanno, Kaidu City, Gifu, Japan). experiment, the second term of equation. (1) and third term of equation (2) are ignorable by employing the cavity resonator. At the temperature of $0^{\circ} \mathrm{C}$ to $100^{\circ} \mathrm{C}$ (region $\mathrm{A}$ ), the temperature of deposited sand with water increases with time (region A). In this region, $\iint \sum_{i} \rho_{i} C_{p}^{i} d T d V$ is equal to $\mathrm{W}_{\mathrm{fp}}-\mathrm{W}_{\mathrm{rp}}\left(=1 / 2 \omega \varepsilon_{r}^{\prime \prime}|E|^{2}\right)$.

The MW power required to increase the mixture (water and soil) temperature considers that $\mathrm{dT} / \mathrm{dt}$ indicates a constant value in this region. (Here, $\mathrm{w}_{\text {out }}$ in the temperatures of $80^{\circ} \mathrm{C}$ and $40^{\circ} \mathrm{C}$ is $\iint_{S} \alpha\left(T_{80}-T_{80-}\right) d S+\iint_{V} \sum_{i} \rho_{i} C_{p}^{i} d T d V$ and $\iint_{S} \alpha\left(T_{40}-T_{-}\right) d S+\iint_{V} \sum_{i} \rho_{i} C_{p}^{i} d T d V$. When $\mathrm{w}_{\text {out }}$ indicates the same value for each temperature, $\int_{S}^{V} \alpha\left(T_{80}-T_{80-}\right) d S$ and $\int_{S} \alpha\left(T_{40}-T_{40-}\right) d S$ should be ignorable with respect to $\left.\iint_{V} \sum_{i} \rho_{i} C_{p}^{i} d T d V\right)$.

At the temperature of $100^{\circ} \mathrm{C}$ (region $\mathrm{B}$ ), almost all $\mathrm{MW}$ energy is required for water vaporization as follows:

$$
\begin{aligned}
& \rho_{H 2 O l} \delta H V_{\text {vapor }}=\frac{1}{2} \omega \varepsilon_{r}^{\prime \prime}|E|^{2} V=W_{f p}-W_{r p} \\
& \Theta=\frac{V_{\text {vapor }}}{V}=\frac{W_{f p}-W_{r p}}{\rho_{\mathrm{H}_{2} \mathrm{O}} \delta H}
\end{aligned}
$$

where $\Theta$ denotes the vaporization rate, $\mathrm{V}_{\text {vapor }}$ is the volume of water vaporization, and $\delta H$ represents the vaporization enthalpy from water to gas. Equation (4) is obtained by equations. (1) to (3) with consideration of the energy balance of equations. (1) to (3) of region B. In this equation, the second term of equation. (2) is ignorable, considering dT/ $\mathrm{dt}$ at $\mathrm{MW}$ off (the maximum value of substrate energy by this term was estimated to be $4.88 \mathrm{~W}$ ). For this equation, experimental data support the theoretical consideration. Furthermore, Figure 3 indicates the actual input power $\left(=\mathrm{W}_{\mathrm{fp}}-\mathrm{W}_{\mathrm{rp}}\right)$ versus the theoretical power estimated by water vaporization mass for $80-\mathrm{W}$ MW (a) and 120-W MW (b). The value of the vertical axis was estimated by the amount of vaporized water: $\rho_{H 2 O l} H V_{\text {vapor }}$.

As shown in Figure 3b, the gradient is 0.977 and the efficiency of water vaporization is almost one. Considering equilibria constant is $10^{-1.497}$ in reaction: $\mathrm{H}_{2} \mathrm{O}(\mathrm{l}) \rightarrow \mathrm{H}_{2} \mathrm{O}(\mathrm{g})$, the error bar of the efficiency is estimated to be 0.03 at the maximum. The gradient indicates the process efficiency and is $\sim 1$. This result indicates that nearly all MW energy was required to vaporize the water.

In terms of absorption properties of water and soil, almost all MW energy was employed for water vaporization as follows. Figures $4 a$

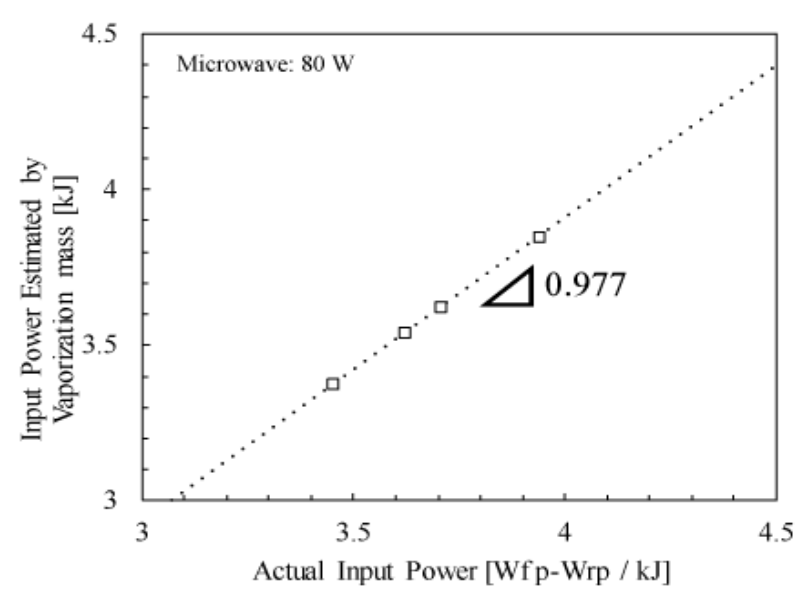

Figure $3(\mathrm{a})$ : Actual input power $\left(=\mathrm{W}_{\mathrm{FP}}-\mathrm{W}_{\mathrm{RP}}\right)$ vs. theoretical power estimated by water vaporization mass for $80 \mathrm{~W} \mathrm{MW}$. 
and $4 \mathrm{~b}$ indicates the MW frequency versus the real part of the relative permittivity and the loss tangent for the water and soil mixture (a). It additionally shows the water obtained by filtering them (b). The loss tangent indicates absorption of MW for the MW frequency; a minimal difference between the mixture and filtered water exist. Considering that the electrical property of dry soil is $\varepsilon_{\mathrm{r}}^{\prime}: 2.55$ and the loss tangent is 0.034 measured by the cavity perturbation method $[6,19]$, the absorption of water is dominant in the deposited sand because the filtered water

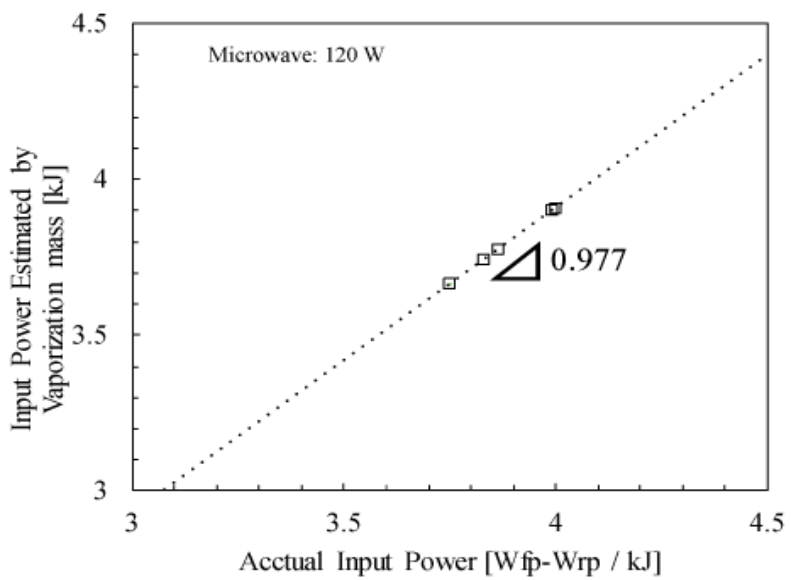

Figure 3 (b): Actual input power $\left(=\mathrm{W}_{\mathrm{FP}}-\mathrm{W}_{\mathrm{RP}}\right)$ vs. theoretical power estimated by water vaporization mass $120 \mathrm{~W}$ MW.

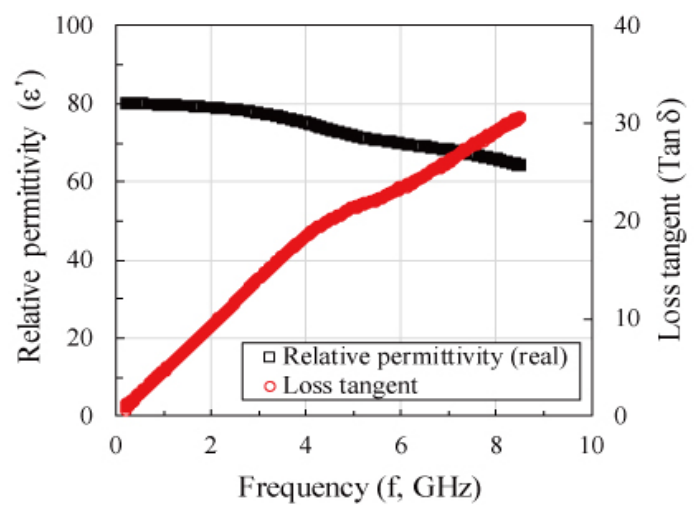

Figure 4 (a): MW frequency vs. real part of relative permittivity and loss tangent for water and soil mixture.

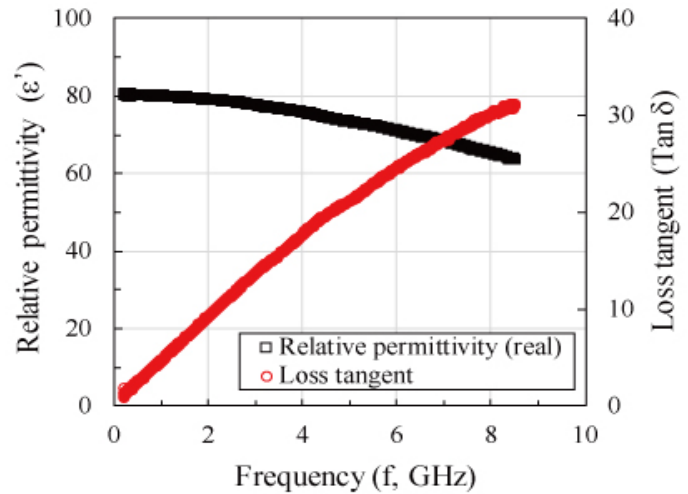

Figure 4 (b): MW frequency vs. real part of relative permittivity water obtained by filtering them. is the same as the deposited sand in terms of the loss tangent. Their absorption probably decreases with temperature increasing considering that the loss tangent of water indicates the same tendency [21]. It is noticeable that their real part of the permittivity decreased, while the loss tangent increased with an increased microwave frequency.

Figure 5 indicates the time versus evaporation rate of water from the soil for each treatment (20-W MW, 80-W MW, and drying furnace). By the electrical furnace, a 10-g mixture requires $2.0 \times 10^{3} \mathrm{~s}$ to be completely dried. The $80-\mathrm{W}$ MW is much shorter than $20 \mathrm{~W}$ in terms of the evaporation time, and the MW indicates different orders of magnitude than the drying furnace process in the water evaporation rate. Furthermore, the vaporization curve increases with MW in the gradient (where $80 \mathrm{~W}$ corresponds to 1.52 and $20 \mathrm{~W}$ corresponds to 0.150 ). This is because the absorption energy of $80 \mathrm{~W}$ is much greater than that of $20 \mathrm{~W}$.

Figure 6a depicts the initial water content versus the water evaporation rate from the soil for MW power ((a) $20 \mathrm{~W}$ ) and each treatment time ((b) $90 \mathrm{~s})$. The dotted line means that the initial water content is equal to the evaporation; the plots near the dotted line are completely dried samples. For $90 \mathrm{~s}$ and $180 \mathrm{~s}$ treatments, the plots display considerable variations, and the drying processes are not steady. These variations decrease with an increased process time, which indicates that the process becomes steady. Furthermore, the water evaporation steadily moves toward the line with increasing process time for

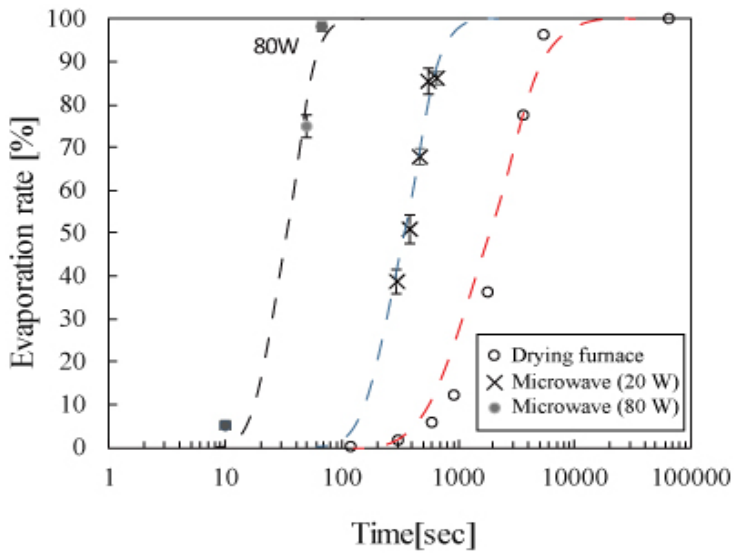

Figure 5: Time vs. evaporation rate of water from soil for each treatment (20 W MW, $80 \mathrm{~W}$ MW and drying furnace).

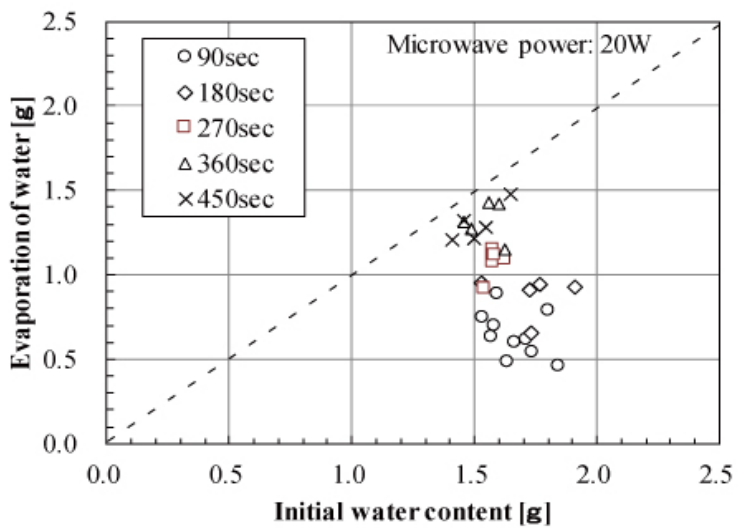

Figure 6 (a): Initial water content vs. evaporation rate of water from soil for each treatment time $(20 \mathrm{~W})$ 
treatment of 20-W MW power, which indicates that the drying process time decreases. The drying process becomes steady with increasing MW power, as shown in Figure 6b. Plots of 20-W MW treatment are far from the dotted line, while plots of $60-\mathrm{W}$ MW are close to this line. This result indicates that the drying time decreases with an increased MW power. Furthermore, 100-W MW-forced soil is almost completely dry by 76 s. As shown in these figures, MW power has a significant effect on the stability of water vaporization, and sufficient time and power makes the MW drying method stable.

To evaluate the application of MW heating to soil modification, the effects of soil aggregating agents on MW water vaporization were examined. Figure 7 shows the MW power versus the vapor rate of water from deposited sand $(\mathrm{N}=3)$ with or without an aggregating agent. Soil aggregating agents show minimal effects on the vapor rate at a low MW power $(80 \mathrm{~W})$. At this $\mathrm{MW}$ power, the spaces between soils are believed to be large enough for water vaporization without agents. The $120-\mathrm{W}$ MW power engendered excess vapor in the soil pathways. In this case, soil-aggregating agents maintained sufficient pathways of water vapor and indicated obvious differences.

\section{Conclusion}

In this study, we investigated the heating behavior of water-soil moisture, water vapor rates, and the effects of soil-aggregating agent permittivity under a $2.45-\mathrm{GHz} \mathrm{MW}$ of a cavity resonator. MW methods indicated rapid vaporization of water in different orders of magnitude

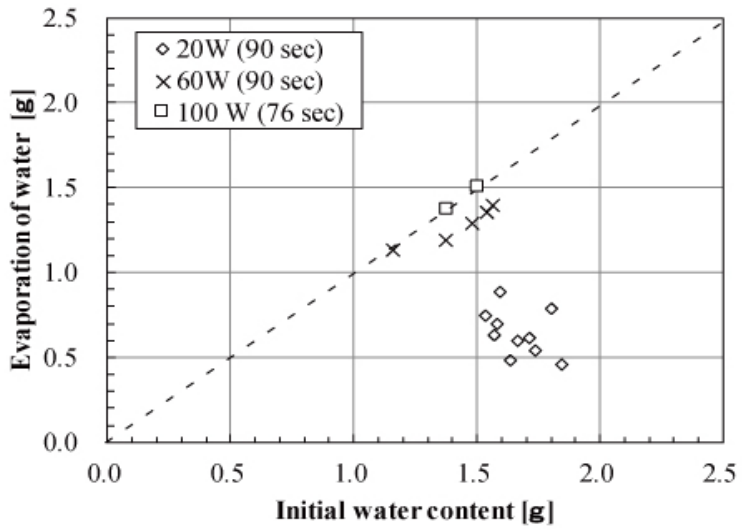

Figure 6 (b): Initial water content vs. evaporation rate of water from soil for each treatment time ((a) $20 \mathrm{~W})$ and MW power ((b) $90 \mathrm{~s})$.

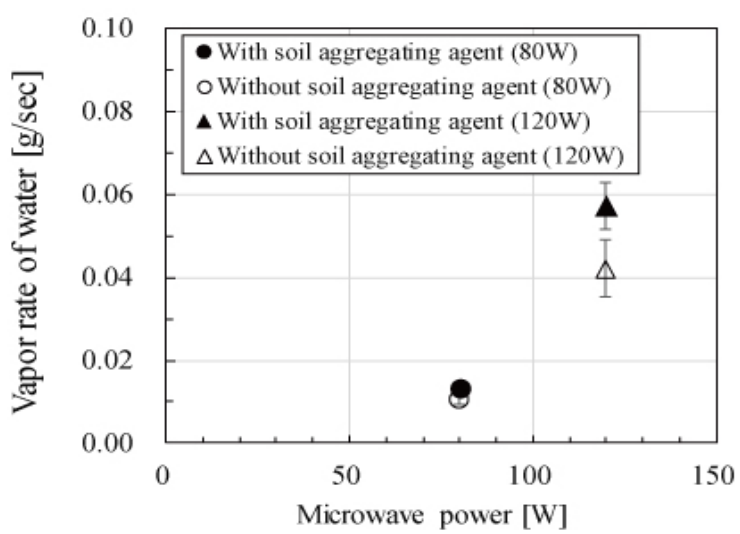

Figure 7: MW power vs. vapour rate of water from deposited sand $(\mathrm{N}=3)$ with or without an aggregating agent. than the drying furnace process. This vaporization mass showed a linear relationship with the MW irradiation time. The vaporization of water conformed to the energy balance between the evaporative latent heat of water and MW power. 97\% MW energy was required for water vaporization according to the calculation of the vaporization mass and MW absorption properties, which indicated that MW heat water exists selectively in the moisture as well. Furthermore, soil-aggregating agents showed minimal effects on the vapor rate at a low MW power, while the deposited sand with aggregating agents indicated a higher vapor rate than that without agents at a high MW power. When sufficient energy was supplied to the moisture, the water transfer was dominant in the vaporization process. In this case, soil-aggregating agents demonstrated a significant effect on the efficiency of the vaporization process.

\section{References}

1. Ishizaki K, Nagata K (2007) Selectivity of microwave energy consumption in the reduction of $\mathrm{Fe}_{3} \mathrm{O}_{4}$ with carbon black in mixed powder. ISIJ Int 47: 811-816.

2. Peng Z, Hwang JY, Andriese M, Bell W, Huang X, et al. (2011) Numerical simulation of heat transfer during microwave heating of magnetite. ISIJ Int 51 884-888.

3. Roy R, Agrawal D, Cheng J, Gedevanshvili S (1999) Full sintering of powderedmetal bodies in a microwave field. Nature 399: 668-670.

4. Yoshikawa N, Tokuyama $Y$ (2009) Numerical simulation of temperature distribution in multi-phase materials as a result of selective heating by microwave energy. J Microw Power Electromagn Energy 43: 27-33.

5. Rybakov KI, Semenov VE, Egorov SV, Eremeev AG, Plotnikov IV, et al. (2006 Microwave heating of conductive powder materials. J Appl Phys 99: 023506.

6. Yoshikawa N, Kashimura K, Hashiguchi M, Sato M, Horikoshi S, et al. (2015) Detoxification mechanism of asbestos materials by microwave treatment. J Hazard Mater 284: 201-206.

7. Kashimura K, Yamaguchi T, Sato M, Saori Y, Kishima K, et al. (2014) Rapid transformation of asbestos into harmless waste by a microwave rotary furnace: Application of microwave heating to rubble processing of the 2011 Tohoku earthquake. J hazard Toxic Radioact Waste 19: 1-5.

8. Miura S, Kawanishi J, Kanemitsu K (1988) Proceedings of the $10^{\text {th }}$ Symposium on Environment and Sanitary Research: 295-298.

9. Mori M, Takahashi H, Ousaka A, Horii K, Kataoka I, et al. (2003) A proposal of new recycling system of high water content mud by using paper debris and polymer and strength property of recycled soils. Shigen to Sozai 119: 155-160.

10. Kamon M, Katsumi T, Inui T (1997) Dehydration-solidification treatment system of waste slurry from construction works. Annuals of Disas Prev Res Inst, Kyoto Univ 40: 1997-2002.

11. Routledge DB, Sabey BR (1976) Use of a microwave oven for moisture determination in a soil science laboratory. J Nat Res Life Sci Education 5: 25-27.

12. Ferriss RS (1984) Effects of microwave oven treatment on microorganisms in soil. Phytopathology 74: 121-126.

13. Kawala Z, Atamanczuk T (1998) Microwave-enhanced thermal decontamination of soil. Environ Sci Technol 32: 2602-2607.

14. Appleton TJ, Colder RI, Kingman SW, Lowndes IS (2005) Microwave technology for energy-efficient processing of waste. Appl Energy 81: 85-113.

15. Barba AA, Acierno D, d'Amore M (2012) Use of microwaves for in-situ removal of pollutant compounds from solid matrices. J Hazard Mater 207-208: 128-135.

16. Jiban KK (2010) Soil test-basics and handbook-. Japanese Geotechnical Society, Japan. pp. 33-38.

17. Roy R, Peelamedu P, Hurtt L, Cheng JP, Agrawal D (2002) Definitive experimental evidence for microwave effects: Radically new effects of separated $\mathrm{E}$ and $\mathrm{H}$ fields, such as decrystallization of oxides in seconds. Mater Res Innov 6: $128-140$.

18. Pickles CA, Mouris J, Hutcheon RM (2005) High-temperature dielectric properties of goethite from 400 to $3000 \mathrm{MHz}$. J Mater Res 20: 18-29.

19. Peng Z, Hwang JY, Mouris J, Hutcheon R, Huang X (2010) Microwave penetration depth in materials with non-zero magnetic susceptibility. ISIJ Int 50: $1590-1596$ 
Citation: Yokawa H, Mutou H, Tsubaki S, Haneishi N, Fuji T, et al. (2017) Water Vaporization from Deposited Sand by Microwave Cavity Resonator. J Civil Environ Eng 7: 279. doi: 10.4172/2165-784X.1000279

20. Blackham DV, Pollard RD (1997) An improved technique for permittivity measurements using a coaxial probe. IEEE Trans Instrum Meas 46: 1093-1099.
21. Von Hippel (1995) Dielectrica materials and application, Artech house publisher, Boston, USA. p. 361. 